\title{
Ética, trabajo social y derecho a la accesibilidad
}

\author{
Ethics, social work and right to accessibility
}

\section{Resumen}

En este trabajo nos ocupamos de la cuestión de la accesibilidad universal desde una perspectiva teórica de engarce entre los derechos humanos y la ética profesional del trabajo social. Aunque se trata de un derecho humano de las personas con diversidad funcional reconocido en la Convención de la ONU de 2006, fundamental para el empoderamiento de su autonomía y para una plena participación social, su implementación dista mucho de ser adecuada en nuestra sociedad. Desde un plano ético justificamos que constituye un compromiso de justicia que, dada la relevancia señalada, requiere de más atención en la formación y en una práctica profesional de los servicios sociales centrada en las personas con diversidad funcional. Finalizamos el texto apuntando algunas implicaciones derivadas de este derecho humano en un enfoque ético del trabajo social.

\section{Palabras clave}

Accesibilidad universal, diseño para todas las personas, personas con diversidad funcional, derechos humanos, ética profesional.

\begin{abstract}
In this paper we address the issue of universal accessibility from a theoretical perspective of linking human rights and the professional ethics of social work. Although it is a human right of people with functional diversity recognized in the 2006 UN Convention, fundamental for the empowerment of their autonomy and for full social participation, its implementation is far from adequate in our society. From an ethical point of view, we justify that it constitutes a commitment to justice which, given the relevance pointed out, requires more attention in training and in a professional practice of social services focused on people with functional diversity. We end the text by pointing out some implications derived from this human right in an ethical approach to social work.
\end{abstract}

\section{Keywords}

Universal accessibility, design for all people, people with functional diversity, human rights, professional ethics.

\author{
Manuel Aparicio Payá \\ $<$ manuel.aparicio@um.es>
}

Universidad de Murcia. España

\section{Susana Rodríguez Díaz} <srodriguez@madrid.uned.es> UNED. España

\section{Para citar:}

Aparicio, M y Rodríguez, S. (2020). "Ética, trabajo social y derecho a la accesibilidad". Revista Española de Discapacidad, 8(I), pp. 25-41.

Doi: <https://doi.org/10.5569/23405104.08.01.02>

Fecha de recepción: 23-06-2019 Fecha de aceptación: 28-05-2020

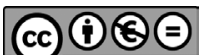




\section{Introducción ${ }^{1}$}

La accesibilidad universal y, correlativamente, el diseño para todas las personas, constituyen, conjuntamente, un derecho humano fundamental de las personas con diversidad funcional. Este derecho está reconocido expresamente en la Convención de la ONU de 2006, después de décadas de reivindicación por parte de diferentes grupos sociales afectados. No obstante, a pesar de los avances sociales en este terreno, es un derecho que requiere todavía de una profunda implementación social, como ponen de manifiesto las insuficiencias detectadas en el mismo por recientes informes sociales (CERMI, 2017; Jiménez y Huete, 2017). La importancia de dicha implementación está ligada a una finalidad de justicia: fomentar el igual ejercicio de la autonomía personal y reducir la discriminación y la exclusión social que sigue afectando a las personas con diversidad funcional. El avance en esta finalidad de justicia constituye una tarea intrínsecamente relacionada con el desempeño profesional de los trabajadores sociales. Este artículo pivota sobre la interrelación entre ética, derechos humanos y trabajo social. En él trataremos de justificar que la ética profesional del trabajo social ha de incorporar este derecho a su acervo de principios éticos orientadores de las tareas de intervención social. Como compromiso ético de justicia, debería priorizarse en la formación de tales profesionales, y también ser objeto de especial atención en su práctica profesional.

Articulamos el trabajo en un conjunto de ideas teóricas conducente a dicha justificación. En primer lugar, se pone de manifiesto el cambio de orientación, derivado de la vigencia de la Convención de 2006, en el trabajo social con personas con diversidad funcional. Este documento jurídico surge bajo la influencia de un nuevo paradigma, el modelo social de la discapacidad (Palacios, 2008). Partiendo de este modelo, la comprensión de la discapacidad y la intervención social correctora se tiene que realizar desde la óptica de los derechos humanos vigentes. Sostenemos que este es el marco ético ineludible al que deben ajustarse los trabajadores sociales. En segundo lugar, nos ocupamos de indagar en el sentido del derecho a la accesibilidad universal en el marco de la Convención. Entendida la accesibilidad universal como el "derecho a tener acceso a los derechos", constituye una condición necesaria para tratar justamente a las personas con diversidad funcional. De ahí su importancia en el ámbito del trabajo social, tradicionalmente centrado en la promoción de los derechos. En un tercer paso, ya en el terreno de la relación entre ética y trabajo social, procedemos a apuntar una fundamentación de este derecho desde diferentes teorías éticas contemporáneas de la justicia (enfoque de las capacidades de Nussbaum, ética del diálogo de Habermas, ética de la razón cordial de Cortina). Esta fundamentación aporta razones normativas para trasladar al ámbito de la ética profesional del trabajo social la asunción de la accesibilidad universal y del diseño para todas las personas como compromiso profesional de justicia. Finalmente, consideramos las consecuencias de la asunción profesional de este compromiso, tanto en la formación como en la práctica de los servicios sociales. Entendemos que, con ello, se realiza una intervención centrada en el pleno reconocimiento de la persona atendida.

1. Este artículo se enmarca en el proyecto de investigación "Capacitismo: haciendo evidente el último prejuicio. Su influencia en el cumplimiento en España de la Convención sobre los Derechos de las Personas con Discapacidad” (FFI2017-88787-R), financiado por el Ministerio de Economía, Industria y Competitividad. 


\section{La Convención de los derechos de las personas con discapacidad como marco de referencia para el trabajo social}

Existe una interconexión entre el fenómeno de la discapacidad y el fenómeno de la exclusión social (Muyor, 2011; González y Mercado, 2019). Por ello, la práctica profesional de los trabajadores y las trabajadoras sociales que atienden a las personas cuyos cuerpos/mentes tienen un funcionamiento distinto al estadísticamente habitual tiene un marco de referencia ineludible en la Convención ONU de 2006 sobre los derechos de las personas con discapacidad (en adelante, la Convención). A nuestro juicio, tal referencialidad queda justificada desde una triple perspectiva:

- La propia tradición profesional: más allá de la labor burocrática realizada en el seno de diferentes instituciones, la búsqueda de la justicia ha constituido tradicionalmente una seña de identidad del trabajo de intervención social. Esta profesión se ha caracterizado por el "descenso a la periferia" (Cortina, 2009a: 14) y el contacto con quienes sufren la exclusión de la aporofobia, como ocurre en numerosas ocasiones con las personas con diversidad funcional (Cortina, 2017: 80-81; Llano, 2018). Tal búsqueda de la justicia ha conllevado que, en la configuración de dicha tradición profesional, se haya apelado a la necesidad de "estudiar los derechos de todos los $\sin$ (sin trabajo, sin techo, sin papeles, sin poderes..." (Robertis, 2003). El conocimiento y el compromiso general con los derechos humanos, extensible ahora también a los derechos recogidos en la Convención, ha de llegar a formar parte de la deontología profesional, en virtud de su obligatoriedad moral-jurídica (Habermas, 2012; Cortina, 2003). También de la ética del trabajador dedicado a la intervención social, dada la necesidad de sortear el peligro de una práctica profesional meramente burocratizada y de defender un ejercicio profesional que tome en consideración la lucha por la justicia social y el reconocimiento de los derechos humanos (Cortina, 2009a; Úriz y Salcedo, 2017)2.

- Por la obligatoriedad moral-jurídica de la formación en aquellas profesiones que se ocupan directamente de las personas con diversidad funcional: la propia Convención establece, en su artículo 4.1. i, que los Estados parte deben "promover la formación de los profesionales y el personal que trabajan con personas con discapacidad respecto de los derechos reconocidos en la presente Convención, a fin de prestar mejor la asistencia y los servicios garantizados por esos derechos". Consecuentemente, los profesionales de los servicios sociales deben recibir una adecuada formación en este campo. Han de conocer los derechos allí recogidos para poder velar por los mismos. Han de trasladar a las instituciones y a los diferentes poderes públicos las necesidades de intervención cuando perciban que tales derechos resultan insuficientemente reconocidos.

- Atendiendo a la realidad social existente: si consideramos los diferentes informes (CERMI, 2017; Jiménez y Huete, 2017) realizados con motivo del décimo aniversario de la Convención en España, se pone de manifiesto la lenta implementación de este documento jurídico internacional en el ámbito legislativo nacional, teniendo en cuenta, además, la dispersión de competencias entre los niveles institucionales central, autonómico y local. El reto que tienen por delante los profesionales del trabajo social es seguir contribuyendo a impulsar, desde las instituciones desde las que prestan servicio, los derechos recogidos en la Convención.

2. La discusión sobre las relaciones entre la reflexión ética y la deontología profesional y su relevancia en el trabajo social puede consultarse en diferentes trabajos (Verde-Diego y Cebolla, 2017; Rodríguez, 2017; Úriz, 2019). 
Por otra parte, se ha de tener en cuenta que asumir el discurso normativo y axiológico subyacente en la Convención, entendiéndolo como una especie de faro-guía de la intervención social con personas con diversidad funcional, implica situar el propio trabajo social en unas nuevas coordenadas (Muyor, 2011; González y Mercado, 2019). La razón de esta recomposición de la profesión en relación con dicho grupo social estriba en la adopción de una concepción distinta del fenómeno de la discapacidad. Concepción que todavía lucha por abrirse camino, muy diferente de la que impregna en buena medida el imaginario social. Nos referimos al cambio de perspectiva teórica adoptada en la Convención, que supone pasar del denominado modelo médico al modelo social de la discapacidad. Aunque este último modelo haya sido bastante discutido, tanto de un punto de vista interno como desde planteamientos externos (Crow, 1997; Hugghes y Paterson, 2008; Seoane, 2011), a nuestro entender lo relevante es - sin olvidar las razones de tales críticas - que no puede obviarse la notable influencia que tuvo en el propio proceso de elaboración y redacción final de la Convención (Palacios, 2008). El discurso predominante en la Convención tiene que ser interpretado, en buena medida, en concordancia con las reivindicaciones germinales de naturaleza éticopolítica (justicia social, reconocimiento de la igual dignidad y derechos humanos para alcanzar una igual ciudadanía de las personas con diversidad funcional) subyacentes en dicho modelo teórico (Barton, 1998).

El modelo social supone un avance histórico en el trato social hacia dichas personas respecto al dado siguiendo el anterior modelo médico. El modelo médico de la discapacidad, originado en la modernidad con el desarrollo científico, cobra gran relevancia desde comienzos del siglo XX. Concibe la discapacidad desde una perspectiva naturalista, considerándola como un conjunto de causas y efectos de origen fisiológico -congénitos o adquiridos-, por lo que se convierte en objeto de la emergente ciencia médica. En ese contexto, la deficiencia corporal se asocia con el concepto de enfermedad, lo que justifica las prácticas médicas que se realizan para la adaptación y normalización de los individuos (Rodríguez y Cano, 2015). La discapacidad queda ligada a unos estándares que el organismo humano debe cumplir en su constitución y funcionamiento para ser clasificado como normal. Desde esta perspectiva, las políticas sociales con las personas con diversidad funcional se circunscriben básicamente al ámbito de su rehabilitación con vistas a la integración social (muchas veces en espacios sociales especiales). La intervención social con tales personas queda caracterizada como un diagnóstico y un tratamiento social a partir de una lógica de curación de aquellos que no se ajustan a la norma, incidiendo en sus aspectos patológicos (Muyor, 2011).

En las últimas décadas del siglo XX se abrió camino, especialmente en el mundo anglosajón, el modelo social de la discapacidad (el modelo médico todavía no ha perdido por completo su vigencia social; de hecho, aún constituye la visión predominante en muchos contextos). Según este punto de vista, la discapacidad está, en última instancia, causada por un entorno social, económico y político injusto, excluyente, manifestado en forma de barreras u obstáculos (Rodríguez y Cano, 2015). Deja, pues, de ser una entidad invariable y se convierte en una relación susceptible de transformación social. Incluso puede resultar anulada, para lo cual es necesaria una actitud transformadora de las relaciones interpersonales (Toboso y Guzmán, 2010). Este nuevo modelo hunde sus raíces en el Movimiento de Vida Independiente, iniciado en Estados Unidos hacia finales de los años sesenta del siglo XX, el cual aboga por los derechos civiles de este colectivo. El discurso crítico que se gesta dentro del propio colectivo se centra en la reivindicación a poder llevar, como las demás personas, una vida independiente. Esto es, reivindica el derecho a decidir sobre su vida, en vez de sujetarse exclusivamente a las directrices señaladas por expertos y profesionales (Rodríguez y Ferreira, 2010). Este movimiento llegó a España de la mano del Foro de Vida Independiente, el cual pasó a denominarse en 2001 Foro de Vida Independiente y Divertad. Esta organización reivindica una vida autónoma para todos, siempre desde el respeto a la diversidad corporal y mental humana. 
Desde este nuevo punto de vista, las políticas sociales que deben ser adoptadas tienen que ver con: a) el respeto y la promoción de los derechos humanos que tales personas tienen en virtud de su igual dignidad; b) la consideración de ciudadanos que han de ser incluidos plenamente en la sociedad, con independencia de su constitución biopsicológica, y c) el diseño justo de los entornos sociales, tanto en sus aspectos materiales, como en sus aspectos culturales y actitudinales. Tal concepción, latente en la Convención, aunque modificada de modo relevante desde la idea del respeto a la diversidad ${ }^{3}$, transforma el sentido de la intervención social. Ésta ha de centrarse en la autonomía que posee la persona con diversidad funcional para vivir de acuerdo con los recursos con que cuenta, con sus posibilidades de decisión y con el apoyo en los derechos que posee para abordar sus necesidades concretas (Muyor, 2011; González y Mercado, 2019). El modelo de intervención social centrada en la persona - teniendo en cuenta su interdependencia de los entornos sociales - y en los derechos establecidos en la Convención:

- Ha de promocionar la autonomía mediante un empoderamiento de la persona con diversidad funcional.

- Con apoyo de tales derechos.

- Contando también con su participación activa en tanto que sujeto (Román, 2018; González y Mercado, 2019).

En el desempeño de esa tarea de intervención social, que toma como centro a la persona y su dignidad, resulta crucial que los profesionales del trabajo social les reconozcan a dichas personas su igual dignidad y los derechos recogidos en la Convención; que faciliten con su trabajo el apoyo efectivo en dichos derechos para lograr su empoderamiento; y que, contando con sus necesidades y aspiraciones personales (González y Mercado, 2019), promuevan su reivindicación ante las instituciones sociales en las que ejercen la profesión, cuando concurran circunstancias que conviertan los derechos en papel mojado.

3. La accesibilidad universal: derecho humano fundamental y garantía de ciudadanía democrática.

Hay que tener en cuenta, tal y como se recoge en su preámbulo, apartados b y c, que la Convención de 2006 constituye una modulación de la Declaración Universal de Derechos Humanos y de los Pactos Internacionales de Derechos Humanos. Se trata de una aplicación a la realidad y necesidades de las personas con diversidad funcional. Su objetivo no es, por tanto, la creación de nuevos derechos, sino su adaptación a las características de las personas que cuentan con algún tipo de impedimento corporal/mental (Palacios, 2008: 270). En tal sentido, el propósito de este documento jurídico internacional, como señala el artículo 1 , es "promover, proteger y asegurar el goce pleno y en condiciones de igualdad de todos los derechos humanos y libertades fundamentales por todas las personas con discapacidad, y promover el respeto de su dignidad inherente". Se trata, según podemos interpretar, de crear iguales condiciones sociales para que los derechos puedan ser universalmente ejercidos, con independencia de cuáles sean las condiciones biopsicológicas concretas que las personas puedan tener en tanto que destinatarios de los mismos.

3. Puede decirse que la referencia que se realiza en la Convención al hecho de la diversidad humana y al respeto a la diferencia introduce una idea que supera el contenido del modelo social. En tal sentido, hay autores (Palacios y Romañach, 2006; Toboso, 2018) que introducen un nuevo modelo teórico a partir de este hecho y de su consecuencia en el plano normativo. 
Por otra parte, la Convención asume - como señalábamos antes - el discurso propio del modelo social de la discapacidad, así como el núcleo de reivindicaciones planteado por diversos colectivos que venían luchando por el reconocimiento (Honneth, 1997) de iguales condiciones de acceso a los derechos. Como se desprende a partir del texto de la Convención, la igual participación en la vida social, sobre la base del pleno ejercicio de los derechos humanos, solo será posible a través de un cambio sociocultural. Dicho cambio habrá de incidir en:

- Una nueva concepción de la discapacidad, que sustituya la visión naturalista predominante en el imaginario social por una concepción que subraye las limitaciones impuestas por el entorno social en la vida social de las personas con diversidad funcional. En la Convención se expresa que "la discapacidad es un concepto que evoluciona y que resulta de la interacción entre las personas con deficiencias y las barreras debidas a la actitud y al entorno que evitan su participación plena y efectiva en la sociedad, en igualdad de condiciones con las demás" (preámbulo, apartado e).

- La importancia fundamental que, para tales personas, tiene la accesibilidad universal. Es relevante la accesibilidad "al entorno físico, social, económico y cultural, a la salud y la educación y a la información y las comunicaciones, para que las personas con discapacidad puedan gozar plenamente de todos los derechos humanos y las libertades fundamentales" (preámbulo, apartado v).

Se ha señalado la complejidad jurídica del concepto de accesibilidad recogido en la Convención: como principio jurídico, como componente de los derechos fundamentales, como exigencia de no discriminación y como derecho a acceder a bienes, productos y servicios (Asís, 2019). Más allá de esta diferenciación, lo que nos interesa ahora es subrayar el carácter universalista que tiene la idea de accesibilidad expresada en ese documento jurídico internacional. Universalismo que conecta con el carácter intrínseco de los derechos humanos, y que lleva, más allá de lo jurídico, al terreno de la obligatoriedad moral hacia la igual dignidad personal (Habermas, 2012). Si la plena inclusión de las personas con diversidad funcional en diferentes entornos sociales (físico, social, económico, cultural) requiere de la configuración social, sustentada jurídicamente, de iguales condiciones de acceso a los mismos, y si dicha accesibilidad, a su vez, es la garantía del pleno goce de cada uno de los derechos humanos, entonces puede decirse que la Convención establece una clara y estrecha vinculación entre el conjunto de los derechos humanos y la accesibilidad universal. Tal vinculación se pone de manifiesto, por ejemplo, en el artículo 3 de la Convención. En este se la concibe como un principio normativo más, en conexión con los demás principios (respeto a la dignidad y autonomía individual, igualdad de oportunidades y no discriminación, inclusión plena y efectiva, respeto por la diferencia y aceptación de la diversidad humana). Este carácter co-fundamental de la accesibilidad universal se sustenta, a nuestro juicio, en el hecho de la diversidad existente en los seres humanos, combinada con la igual dignidad que abarca a todos ellos, en tanto que esta exige el respeto a la diferencia biopsicológica. $\mathrm{Si}$, en un ejercicio imaginativo, elimináramos el principio de accesibilidad universal, esto significaría tanto como restar dignidad y suprimir o limitar derechos a aquellas personas cuya constitución corporal/mental se aleja de la que posee la mayoría. Por ejemplo: sin accesibilidad en el puesto de trabajo, una persona con diversidad funcional tendría muchos más problemas que los actuales para disponer de un efectivo derecho al trabajo. En tal caso, podría decirse que quedaría mermada la calidad de su vida, al tratarse de un componente considerado ampliamente como integrante de una vida digna. En tanto que co-principio normativo fundamental, la accesibilidad constituye, pues, un valor fundamental que debe ser promocionado. Valor que tiene en cuenta el hecho de la diversidad biopsicológica humana. La diversidad no altera la igual dignidad 
personal, pues esta se sitúa en un plano normativo, a diferencia del plano fáctico-descriptivo en el que nos situamos cuando hablamos de tal diversidad.

La accesibilidad universal remite así a la exigencia de igualdad de condiciones proporcionadas por la sociedad para la protección, la promoción y el disfrute efectivo del conjunto de los derechos humanos. Como principio normativo, sustituye una inclusión social bajo condiciones homogéneas de igualdad, por una inclusión social que atiende a la diversidad biopsicológica de los ciudadanos. Es decir, por una inclusión igualitaria abierta a la diferencia (Habermas, 2008). Se trata, pues, de evitar la discriminación sufrida por las personas con diversidad funcional, teniendo en cuenta los diferentes tipos y la amplitud de rangos que presenta la diversidad humana (preámbulo, apartado i). Desde esa óptica, su sentido normativo no es otro que empoderar la autonomía en el ejercicio del propio plan de vida y favorecer la participación social de todos los ciudadanos. El trabajo social, al luchar contra toda forma de discriminación, ha de centrarse también en la accesibilidad, como modo de ruptura con una homogeneización social excluyente y como apertura de vías al ejercicio de la autonomía y la participación social.

La Convención no se limita a considerar la accesibilidad como principio normativo fundamental. En el artículo 9 de la Convención se hace referencia a diferentes medidas y distintos ámbitos de aplicación de las mismas para alcanzarla. A nuestro juicio, puede entenderse, ahora en un sentido restringido, que se trata de un derecho ligado a los aspectos materiales y culturales de los entornos sociales. Paralelamente, este derecho exige normativamente el diseño de productos, entornos (físico, social, económico, cultural, educativo, etc.), programas y servicios - entre los cuales se encuentran también los servicios sociales - que puedan utilizar todas las personas o, al menos, el mayor número de ellas (artículo 2). Entendemos que esta visión jurídico-instrumental no establece una diferenciación, sino que, más bien, queda integrada en el carácter constitutivo que, a nuestro juicio, tiene la accesibilidad universal. Dicha integración se explica porque los derechos humanos incluyen, para que sean respetadas las diferencias de constitución biopsicológica de sus destinatarios, iguales condiciones de acceso a los mismos (carácter constitutivo). Lo cual requiere, a su vez, del diseño de instrumentos técnicos y/o de acciones pragmáticas (carácter instrumental) que permitan empoderar a las personas para que puedan ejercerlos (Winner, 2007). Un ejemplo puede aclarar esta afirmación: el principio de accesibilidad exige que el derecho a la educación pueda ser ejercido de forma igualitaria por las personas con diversidad funcional (carácter constitutivo), para lo cual se requiere que los entornos escolares diseñen medidas de accesibilidad física, cognitiva o sensorial (carácter instrumental).

De acuerdo con la concepción que hemos expuesto sobre la accesibilidad universal, puede colegirse que:

- Interpretada la accesibilidad universal como el "derecho a tener acceso a los derechos", la negación, la obstaculización, la ausencia de promoción progresiva o la postergación indefinida de la misma equivale a convertir a las personas con diversidad funcional en "personas sin derechos" o, cuando menos, en "personas con derechos restringidos". Tales situaciones afectan a su efectiva inclusión social, lo que las aleja de una ciudadanía plena. De ahí la relevancia de este principio fundamental para la profesión del trabajo social. Una profesión que incide éticamente en el reconocimiento de los derechos y en la búsqueda de la justicia social (Úriz y Salcedo, 2017).

- Es necesario incidir en el diseño de entornos universalmente accesibles, como medios facilitadores para el empoderamiento de las personas con diversidad funcional. Tal diseño es una exigencia jurídicomoral para que estas puedan desarrollar una vida autónoma con plena participación en las distintas 
dimensiones de la sociedad (educación, trabajo, ocio, etc.). Dicha exigencia se ha de traducir en un conjunto de tareas sociales sumamente necesarias para que dichas personas puedan ejercer una autonomía apoyada en sus derechos humanos. En consecuencia, la atención al diseño para todas las personas, como requisito instrumental para el desenvolvimiento de una vida autónoma, también habrá de constituir una dimensión fundamental de las tareas profesionales de los servicios sociales.

\section{La accesibilidad universal como compromiso de justicia en el trabajo social}

Una de las características que parecen definir la profesión de trabajo social es el enfrentamiento con responsabilidad a los retos éticos y políticos existentes en la sociedad (Banks, 2013). Sin duda, pese a los avances conseguidos en las últimas décadas, uno de los grandes retos sociales actuales sigue siendo la plena inclusión social de las personas con diversidad funcional. Para afrontarlo, sigue resultando imprescindible la profundización, continuada en el tiempo, en la construcción de entornos sociales universalmente accesibles ${ }^{4}$, siendo esta una cuestión compleja y siempre abierta en una sociedad que está en constante transformación científico-tecnológica (Cortina y Serra, 2016). En último término, se trata de hacer de la sociedad un entorno que reconozca a las personas con diversidad funcional (Honneth, 1997). Este es un reto ético-político que ha de impregnar la reflexión y la práctica de la intervención social con dichas personas.

Sin duda, la ética constituye una de las preocupaciones teórico-prácticas más importantes de la reflexión reciente sobre este campo profesional (Román, 2016; Úriz y Salcedo, 2017; Raya et al., 2018; Úriz, 2019). La justificación ética de la accesibilidad universal como compromiso de justicia en la ética profesional del trabajo social requiere que nos centremos en los siguientes aspectos:

- Una de las características específicas del desempeño profesional de los trabajadores sociales ha sido, tradicionalmente, asumir el conflicto entre el cumplimiento de las obligaciones hacia las personas para las cuales trabajan y las obligaciones derivadas del marco institucional en el que se inserta su labor. Se trata de una profesión que vive la tensión entre lo que sería justo hacer y lo que de hecho se hace. Dicha tensión conlleva, en último término, el deber de defender a los clientes de la injusticia y asumir el compromiso con una transformación social orientada a conseguir mayores cotas de justicia y de cumplimiento efectivo de los derechos humanos (Salcedo, 2010; Úriz y Salcedo, 2017). En este sentido, en el código ético de la NASW figura, como rasgo definitorio de la profesión de trabajo social, el principio de lucha contra la injusticia y la transformación de la sociedad: "Ios trabajadores sociales persiguen el cambio social, particularmente con y por cuenta de los individuos vulnerables y oprimidos" (NASW, 2010). La transformación profunda hacia una sociedad universalmente accesible sigue siendo, por su carácter todavía incipiente y por la complejidad de factores encerrados (políticos, económicos, jurídicos, culturales, científico-tecnológicos, formativos, etc.), una tarea abierta para los trabajadores socia-

4. El informe CERMI (2017) pone de manifiesto las importantes lagunas de la accesibilidad universal en España. Otro dato relevante es que todavía no se ha puesto en marcha el II Plan Nacional de Accesibilidad 2018-2026. Como otro botón de muestra, encontramos diferentes noticias en los medios de comunicación que denuncian tal situación, como por ejemplo, la indicada en El País, 13-6-2019: https://elpais.com/sociedad/2019/06/12/actualidad/1560334356_594699.html?rel=mas. 
les. Tarea en defensa de los áporoi que, en buena medida, son las personas con diversidad funcional (Cortina, 2017: 80-81). En esa ocupación, han de tenerse en cuenta desde los aspectos microsociales de la accesibilidad, más básicos y cercanos (pensemos, por ejemplo, en la accesibilidad a la vivienda en una comunidad de vecinos), hasta aquellos otros que constituyen estructuralmente el ámbito macrosocial (por ejemplo, los sistemas de transporte público o la investigación en nuevas tecnologías).

- Uno de los aspectos de mayor confluencia entre la profesión de trabajo social y la ética es la atención a los grupos y a las personas vulnerables.

La reflexión ética contemporánea, sin olvidarse de la autonomía, ha puesto de relieve la importancia moral que tiene la atención a la vulnerabilidad humana. Desde diferentes concepciones éticas (Maclntyre, Habermas, Nussbaum, Cortina, etc.) se entiende el comportamiento moral como una respuesta frente a la vulnerabilidad antropológica y social que rodea a la persona. Dicha vulnerabilidad exige la configuración de sociedades que traten con justicia a aquellos grupos o personas más vulnerables.

También la vulnerabilidad tiene fuerte presencia en la profesión del trabajo social. El bien interno específico que, en último término, da sentido a las labores de intervención social es el trabajo por las necesidades y los derechos de los diferentes colectivos de personas vulnerables, la atención a aquellos grupos que la sociedad margina y excluye (Cortina, 2009a). En tal sentido, el código ético de la NASW señala, en su preámbulo, que el principal objetivo de dicha práctica profesional es "elevar el bienestar humano y ayudar a satisfacer las necesidades básicas humanas, con atención en particular a las necesidades y potenciación de la persona que es vulnerable, oprimida y que vive en la pobreza". Ese aumento del bienestar de las personas vulnerables ha de ser compatible con el respeto a la autonomía de los clientes (Salcedo, 2010), por lo cual el objetivo es empoderar a tales personas para que puedan desarrollar autónomamente su plan de vida. Ahora bien, tal empoderamiento solo es posible, como bien señala el código NASW en su preámbulo, si se atiende "a las fuerzas del entorno que crean, contribuyen a, y solucionan los problemas de la vida". Ciertamente, todas las personas somos inter-dependientes (Cortina, 2017: 100) en y del entorno social. Como se subraya desde el modelo social de la discapacidad y desde la Convención, son las transformaciones que pueden producirse en el entorno, en la dirección de la accesibilidad universal, lo que permite el empoderamiento de las personas con diversidad funcional para potenciar una autonomía inter-dependiente en dicho entorno. La atención a la transformación de los diferentes entornos en los que desenvuelven su vida dichas personas es una tarea crucial para lograr su empoderamiento. Por eso, el trabajo social centrado en la persona con diversidad funcional no puede ser ajeno a la transformación de los diferentes entornos sociales en los que esta desenvuelve su vida.

- Desde las teorías éticas contemporáneas se ha fundamentado la inclusión social. También encontramos elementos en ellas para la justificación del principio de accesibilidad universal y del diseño para todas las personas, concibiéndolos como compromisos de justicia:

a. Una de las teorías éticas contemporáneas que proporcionan una fundamentación filosófica de accesibilidad universal es la ética del discurso de Habermas. Su base neokantiana remite al universalismo moral que defiende la igual dignidad de toda persona y, por tanto, la igualdad de derechos que debe extender a toda persona un sistema democrático (Habermas, 2012). El valor fundamental de la dignidad humana ha de ponerse en interrelación con el valor de la diferencia derivada de la propia diversidad humana. A su vez, esta debería enmarcarse en una concepción universalista de la igualdad: debe darse una igualdad no homogeneizadora, sino respetuosa con la diferencia (Habermas, 2008a), con el fin de poder evitar toda forma de exclusión. Desde estas 
premisas, entender que la diversidad biopsicológica humana exige formas universales de acceso a los derechos y a los entornos sociales se justifica por el respeto a la igual dignidad y diferencia de toda persona, y por la exigencia de ser tratado como ciudadano sin ninguna restricción discriminatoria (Habermas, 2008b). Esta igualdad como ciudadano con la misma dignidad se entiende, desde su concepción ética del discurso, en el sentido de ser tratado como un interlocutor válido, de forma que, en tanto que participante pleno en las diferentes facetas de la sociedad, pueda ser, además de destinatario del conjunto de derechos, su autor (Habermas, 2008a). Desde esta óptica, podríamos decir que la accesibilidad universal es un medio facilitador para llegar a poder ser, desde un punto de vista fáctico, un interlocutor válido. También sería un requisito social constitutivo para ser reconocido como tal. Para el filósofo alemán, la individualidad personal se configura a través del proceso de socialización (Habermas, 2008b). Consecuentemente, sin adecuada accesibilidad en los entornos sociales quedan afectados el propio desarrollo biopsicológico y la formación simbólica sin daño de la identidad personal. Lo que se pierde es la garantía de igual acceso a los mismos derechos (como destinatario) y su igual reconocimiento como interlocutor válido para establecerlos (como autor).

Esta concepción normativa tiene consecuencias en el propio modo de entender y configurar la intervención social. Dicha tarea ha de centrarse en la persona inserta en sus entornos, la cual debe ser reconocida como interlocutora válida a lo largo de todo el proceso. Es decir, la persona tiene que ser tratada no como mera observadora del mismo, sino que tiene que llegar a ser participante activa en él en tanto que sujeto. La intervención social no solo tendrá que incidir en la mejora de la accesibilidad a los entornos sociales y a los derechos; también implicará que haya de ajustarse a condiciones de accesibilidad.

b. Lo que aporta el enfoque ético de la razón cordial de Cortina al procedimentalismo ético habermasiano es el descubrimiento de la ligatio en que ya nos encontramos, previo a la vinculación comunicativa entre los sujetos (Cortina, 2009b: 214-215). Los ciudadanos ya somos interdependientes en y de los distintos entornos sociales en los que convivimos. Necesitamos apoyo justo para sacar adelante nuestros proyectos vitales. Necesitamos, en grado variable, empoderar nuestra autonomía. Podemos tener, ahora o en el futuro, necesidades similares en el acceso a derechos, bienes y servicios, al reconocernos como personas de igual "carne y hueso" (Cortina, 2009b: 215), vulnerables. Otra idea fundamental de esta autora es situar en el sentimiento compasivo lo que mueve a adoptar dialógicamente compromisos de justicia (Cortina, 2009b: 190). La compasión desde la igualdad resulta básica para la transformación de los entornos sociales, empoderando a las personas que son vulnerables.

c. La filósofa norteamericana Martha Nussbaum, con su enfoque de las capacidades, ha abordado la justificación del diseño de una sociedad accesible a partir de una teoría parcial de la justicia distributiva (Nussbaum, 2007). Desde su punto de vista, la exclusión sufrida por las personas con diversidad funcional no ha obedecido tanto a sus características naturales como a un diseño de los entornos sociales discriminatorio, al no tener en cuenta las necesidades atípicas de este grupo social. Tal exclusión, a su vez, tiene un origen en la estigmatización a que se somete a dicho grupo. Para Nussbaum, la aspiración a la justicia —latente en la ética profesional del trabajo social— exige un rediseño del espacio público como respuesta moral-política ante la común vulnerabilidad humana, con la finalidad de crear espacios sociales facilitadores para todos. Tal respuesta reconoce el igual "derecho a ser tratado como un ciudadano, como aquél para el que está diseñado el espacio públi- 
co y en cuyo interés se lo mantiene" (Nussbaum, 2006: 353). Este trato igualitario, que garantiza la igualdad de oportunidades, requiere de políticas públicas que aporten capacidades u oportunidades reales que contribuyan a mejorar la calidad de vida de tales personas. La accesibilidad universal y el diseño de los entornos sociales para todas las personas aportan, al menos en un nivel mínimo de justicia, oportunidades reales para llegar a alcanzar una vida autónoma de calidad (Nussbaum, 2007). Si extraemos las consecuencias derivadas de esta concepción teórica, la intervención social constituiría una forma de asistencia a las personas con diversidad funcional en los diferentes tipos de capacidades u oportunidades reales (salud, integridad física, educación, trabajo, ocio, etc.). Por eso, en la intervención social se ha de trabajar para asentar entornos sociales facilitadores, sin olvidar que el propio trabajo social es también un medio facilitador del empoderamiento de tales personas.

Haciendo un balance de este apartado, el compromiso de la profesión con la transformación social, el trabajo desarrollado profesionalmente con los grupos de personas vulnerables y las razones aportadas desde la fundamentación filosófica de la accesibilidad universal, parecen avalar el compromiso ético del trabajo social con dicho principio fundamental.

\section{La accesibilidad universal en la formación y en la intervención social}

La relevancia nuclear del principio ético-jurídico de la accesibilidad universal para las personas con diversidad funcional ha de conllevar consecuencias tanto en la formación de los futuros profesionales como en el ejercicio responsable de las intervenciones sociales. Podemos apuntar una triple perspectiva en que debe ser abordado este compromiso ético, que refuerza y complementa su dimensión jurídica, en las tareas del trabajo social:

\section{Perspectiva formativa}

La Conferencia de Rectores de las Universidades Españolas, en función de las obligaciones derivadas de la Convención y de la legislación española que la desarrolla, ha incidido en la necesidad de formación curricular sobre accesibilidad universal y diseño para todas las personas (Fundación ONCE y CRUE, 2014). Lo cual está en consonancia con las obligaciones de los Estados miembro de la Convención. A nuestro juicio, dicha formación, en su dimensión ética, debería incluir:

1. La dimensión sociohistórica de la lucha por el reconocimiento llevada a cabo por los colectivos de personas con diversidad funcional, como auténtica memoria histórica que contribuya a sensibilizar a los futuros profesionales de la responsabilidad por la justicia (Young, 2011) y los derechos humanos que tendrán en su labor social.

2. Formación ética (Cordero, 2013) que aborde el respeto a la diversidad humana en toda su amplitud biopsicológica, contribuyendo así al reconocimiento de las personas (Honneth, 1997; Román, 2018) 
con las que habrán de trabajar posteriormente y que concite la reflexión sobre las transformaciones del entorno cultural para aminorar o evitar la estigmatización sufrida por ellas.

3. Formación ética que contribuya a azuzar la sensibilidad de los profesionales del trabajo social ante la injusticia (Cortina, 2009a). Tal formación es necesaria para detectar y evaluar situaciones de injusta inaccesibilidad en los diferentes entornos sociales.

4. Formación ética sobre diferentes aspectos de las nuevas tecnologías (Cabezas, 2013; Cortina y Serra, 2016) que facilitan la accesibilidad universal y la participación social en los espacios físicos y/o virtuales y en los diferentes entornos (educación, trabajo, ocio, etc.). Hay que tener en cuenta que el ejercicio de los derechos humanos está conectado, para cualquier persona, con disponer de adecuados medios socio-técnicos (Winner, 2007).

5. Formación ético-social para favorecer una investigación responsable y crítica sobre los aspectos políticos, normativos y sobre la realidad social (en sus aspectos descriptivos, evaluativos y prospectivos) de la accesibilidad universal. Una investigación social responsable y emancipadora en trabajo social no es neutral respecto a los valores, sino que se orienta desde el valor de la justicia y del respeto a los derechos humanos.

6. Formación sobre la responsabilidad social corporativa y la responsabilidad profesional sobre investigación e innovación en diseño para todas las personas.

\section{Perspectiva de promoción de la accesibilidad y el diseño para todos}

La práctica ética del trabajo social también está ligada a la adquisición de competencia profesional mediante la correspondiente adquisición de conocimientos técnico-pragmáticos (Cortina, 2009a). En concreto, sobre la accesibilidad universal y el diseño para todas las personas, en sus diferentes aspectos (jurídicos, sociales, técnicos), en sus ámbitos (educación, trabajo, salud, urbanismo, cultura, ocio, etc.) y en las diferentes áreas (movilidad, comprensión, comunicación, etc.) de aplicación. Este conocimiento constituye la base para llevar a cabo los correspondientes procesos de intervención social, en colaboración también con profesionales de otros campos. Dichas intervenciones tienen que dar a conocer medios e impulsar innovaciones que contribuyan a la transformación estructural hacia una sociedad universalmente accesible. Todo ello para proporcionar bienestar, mayor autonomía y capacidad de autodeterminación a las personas con diversidad funcional en su inclusión en la vida social.

\section{Perspectiva del reconocimiento de la persona como sujeto de intervención social}

Otra perspectiva que debe ser tenida en cuenta en una intervención social realizada desde parámetros éticos es la contribución de la accesibilidad universal y del diseño para todas las personas al reconocimiento de la persona atendida (Honneth, 1997; Román, 2018).

Si la propia intervención social ha de promocionar la autonomía mediante un empoderamiento de la persona con diversidad funcional, teniendo en cuenta sus derechos y contando también con su participación activa (Román, 2018), entonces tal intervención ha de ser diseñada para que, en su proceso y en su resultado, sea accesible al sujeto acompañado. Lo cual requiere que tal intervención sea diseñada de forma que pueda 
constituir un marco facilitador en la toma de decisiones de la persona afectada (Fundación ONCE y CRUE, 2014: 77-78). El diseño de la intervención social como un marco facilitador aporta las diferentes dimensiones del reconocimiento personal (Honneth, 1997. Román, 2018): a) Reconocimiento cuidadoso de la constitución biopsicológica de la persona. Al estar la intervención social misma sujeta a condiciones de accesibilidad (por ejemplo, al compartir los objetivos de intervención social de forma que sean comprensibles a aquellas personas con limitaciones cognitivas), se estará teniendo en cuenta el reconocimiento explícito de las necesidades derivadas de dicha constitución corporal/mental; b) También supone el reconocimiento de su igual acceso al derecho a participar - en tanto que sujeto - activa y autónomamente en tal proceso de intervención social (art. 28 de la Convención); c) Dicho diseño supone la solidaridad del trabajador social con la persona atendida en la diversidad de capacidades que posee. Es desde la solidaridad con las capacidades de la persona como se debe comenzar a trabajar para facilitar su empoderamiento, orientándola hacia el desenvolvimiento lo más autónomamente posible en entornos sociales.

\section{Conclusiones}

La relevancia ético-jurídica de la Convención de 2006 y la centralidad que en ella ocupa la accesibilidad universal ha de suponer un refuerzo en el cambio de coordenadas desde el que ha de realizarse un trabajo social éticamente comprometido con las personas con diversidad funcional. En consecuencia, es imprescindible que dicho marco normativo sea ampliamente difundido en la formación de los futuros profesionales y que las intervenciones sociales resulten coherentes con él. Los servicios sociales, sobre el trasfondo de su propia tradición, han de abordar la brecha entre aquella normatividad y la realidad social vivida por dichas personas. El encuadramiento de las labores de trabajo social en el marco de la Convención no solo responde a la obligatoriedad jurídica, sino que también constituye —como hemos defendido— una preocupación ética que ha de estar presente en esta práctica profesional, orientada por el compromiso de justicia con el cumplimiento de los derechos humanos. De este modo, la labor profesional de raíz ética reforzará el cambio cultural imprescindible para favorecer la necesaria transformación social hacia una más plena inclusión de las personas con diversidad funcional. La labor de intervención social contribuirá así a dar un cumplimiento más efectivo del marco jurídico interno, establecido de acuerdo con la Convención. Dada la realidad de la problemática vivida diariamente por muchas personas con diversidad funcional, se requiere de una intensificación en este campo del trabajo social.

En ese marco normativo ético-jurídico hemos diferenciado dos dimensiones respecto al modo de entender la accesibilidad universal: a) su carácter constitutivo de principio ético-jurídico y parte integrante del conjunto de los derechos, en tanto que estos requieren iguales condiciones de acceso y b) su carácter instrumental en relación a disponer de bienes, productos y servicios a los que puedan acceder también, con menor complejidad, las personas con diversidad funcional. Por un lado, hemos propuesto que la accesibilidad universal en el primer sentido — concebida como el "derecho a tener acceso a los derechos" - llegue a formar parte del acervo de principios orientadores del trabajo social. Tendría entonces una mayor repercusión en la formación ética recibida en los estudios universitarios en este terreno y en el ejercicio de la posterior labor profesional. Tratándose de un principio fundamental de la Convención, no puede olvidarse que constituye un valor-guía 
del conjunto de las profesiones. Máxime si tenemos en cuenta que cualquier profesión cobra sentido social cuando es ejercida para el conjunto de los ciudadanos, sin ningún tipo de exclusión. Así se podrá contribuir a una mayor efectividad de los derechos de las personas atendidas, pues en cada uno de tales derechos está incluida la condición constitutiva de poder tener acceso a ellos. Hemos defendido que la preocupación teórico-práctica por el enfoque ético del trabajo social y la fundamentación de la accesibilidad universal y el diseño para todas las personas desde la reflexión ética contemporánea justifica la propuesta. Hemos mostrado, en tal sentido, que algunas teorías éticas de la justicia (la ética dialógica de Habermas, la reformulación cordial de dicha ética propuesta por Cortina, también el enfoque de las capacidades de Nussbaum) contribuyen a dicha fundamentación. Por otro lado, en lo que respecta a la dimensión instrumental, hemos puesto de manifiesto que debe abarcar, de forma coherente, también a los propios servicios sociales. Los profesionales del trabajo social han de concebir las intervenciones sociales desde el diseño para todas las personas. Con tal diseño, el servicio social ha de resultar accesible a las personas a quienes da asistencia empoderadora.

Ambas dimensiones están implicadas en una intervención social que ha de estar centrada en las personas, que ha de pivotar sobre su reconocimiento. Otra conclusión del trabajo guarda relación con la conexión entre el reconocimiento de la persona atendida y el diseño universal de la intervención social. Hemos apuntado que un servicio de intervención social ajustado al diseño facilitador supone el reconocimiento de la persona acompañada en las diversas dimensiones en que se descompone analíticamente dicho reconocimiento (Honneth, 1997; Román, 2018). El diseño para todas las personas convierte la intervención social, orientada al fomento de la accesibilidad de los diferentes entornos en que se desenvuelve la vida de la persona, en una intervención que resulta ella misma accesible. 


\section{Referencias bibliográficas}

Asís, R. de (octubre, 2019): La accesibilidad universal desde la perspectiva jurídica. Comunicación presentada en Congreso Internacional Elkartuz "Discapacidad, Derechos e Inclusión”, Donostia-San Sebastián. Recuperado de https://elkartu.org/elkartuz/doku/informe_rafael_asis.pdf

Banks, S. (2013). “Prólogo”. En L. M. Rondón y M. L. Taboada: Voces para la ética del Trabajo Social en tiempos trémulos". Madrid: Paraninfo.

Barton, L. (1998). "Sociología y discapacidad: algunos temas nuevos”. En L. Barton (comp.), Discapacidad y Sociedad (pp. 19-33). Madrid: Morata.

Cabezas, J. L. (2013). "Trabajo social y ética ante las nuevas tecnologías: reflexiones ante los retos del tercer milenio”. En L. M. Rondón y M. L. Taboada: Voces para la ética del Trabajo Social en tiempos trémulos. Madrid: Paraninfo.

CERMI (2017). Derechos humanos y discapacidad. Informe España 2016. Madrid: Comité Español de Representantes de Personas con Discapacidad y Ediciones Cinca.

Cordero, N. (2013). "Repensando la formación ética en Trabajo Social: razones, fundamentos y experiencias". En L. M. Rondón y M. L. Taboada: Voces para la ética del Trabajo Social en tiempos trémulos. Madrid: Paraninfo.

Cortina, A. (2003). Razón pública y éticas aplicadas. Madrid: Tecnos.

Cortina, A. (mayo, 2009a). Ética, servicios sociales y ciudadanía. Conferencia inaugural del I Simposio de ética aplicada a la intervención social, Girona. Recuperado de http://www.xiass.cat/wp-content/uploads/\%C3\%89ticaservicios-sociales-y-ciudadan\%C3\%ADa-Adela-Cortina-_28.05.2009_.pdf

Cortina, A. (2009b). Ética de la razón cordial. Educar en la ciudadanía en el siglo XXI. Oviedo: Ediciones Nobel.

Cortina, A. (2017). Aporofobia, el rechazo al pobre. Un desafío para la democracia. Barcelona: Paidós.

Cortina, A. y Serra, M. A. (coords.) (2016). Ética de las tecnologías emergentes en personas con diversidad funcional. Madrid: Ediciones Internacionales Universitarias.

Crow, L. (1997). "Nuestra vida en su totalidad: renovación del modelo social de la discapacidad”. En J. Morris (ed.), Encuentros con desconocidas. Feminismo y discapacidad (pp. 234-235). Madrid: Narcea.

Fundación ONCE y CRUE (2014): Formación curricular en diseño para todas las personas en Trabajo Social. Madrid: CRUE.

González, D. y Mercado, E. (2019). "El modelo social como perspectiva de Intervención desde el Trabajo Social en personas con la capacidad modificada". Revista Española de Discapacidad, 7 (I), pp. 241-249.

Habermas, J. (2008a). La inclusión del otro. Barcelona: Paidós.

Habermas, J. (2008b). Entre naturalismo y religión. Barcelona: Paidós.

Habermas, J. (2012). "El concepto de dignidad humana y la utopía realista de los derechos humanos". En La constitución de Europa (pp. 16-21). Madrid: Trotta.

Honneth, A. (1997). La lucha por el reconocimiento. Por una gramática moral de los conflictos sociales. Barcelona: Crítica. 
Hugghes, B. y Paterson, K. (2008). "El modelo social de la discapacidad y la desaparición del cuerpo". En L. Barton (comp.), Superar las barreras de la discapacidad (pp. 107-123). Madrid: Morata.

Jiménez, A. y Huete, A. (coords.) (2017). Informe Olivenza 2017, sobre la situación general de la discapacidad en España. Madrid: Observatorio Estatal de la Discapacidad.

Llano, J. C. (2018). El estado de la pobreza. Seguimiento del indicador de pobreza y exclusión social en España 2008-2017. Madrid: EAPN España.

Muyor, J. (2011). "La (con)ciencia del Trabajo Social en la discapacidad: Hacia un modelo de intervención social basado en derechos". Documentos de Trabajo Social, 49, pp. 9-33.

Naciones Unidas (2006). Convención sobre los Derechos de las Personas con Discapacidad. Nueva York: ONU.

NASW (National Association of Social Workers) (2010): Código de Ética. Washington, D. C.: NASW.

Nussbaum, M. (2006). El ocultamiento de lo humano: repugnancia, vergüenza y ley. Buenos Aires: Katz.

Nussbaum, M. (2007). Las fronteras de la justicia. Barcelona: Paidós.

Palacios, A. (2008). El modelo social de la discapacidad: orígenes, caracterización y plasmación en la Convención Internacional sobre los Derechos de las Personas con Discapacidad. Madrid: Ediciones Cinca.

Palacios, A. y Romañach, J. (2006). El modelo de la diversidad. La bioética y los derechos humanos como herramienta para alcanzar la plena dignidad en la diversidad funcional. Madrid: Diversitas.

Raya, E. et al. (coords.) (2018). Ciencia y Esencia en la Práctica del Trabajo Social. Valencia: Tirant Humanidades.

Robertis, C. de (2003). Fundamentos del Trabajo Social. Ética y metodología. Valencia: Universitat de Valencia; Nau Llibres.

Rodríguez, J. (2017). "Por la reflexión moral, contra los códigos de ética en el Trabajo Social”. Cuadernos de Trabajo Social, 30(1), pp. 97-108.

Rodríguez, S. y Cano, A. (coords.) (2015). Discapacidad y políticas públicas. La experiencia real de los jóvenes con discapacidad en España. Madrid: Los Libros de la Catarata.

Rodríguez, S. y Ferreira, M. A. (2010). "Desde la dis-capacidad hacia la diversidad funcional. Un ejercicio de disnormalización”. Revista Internacional de Sociología, 68, pp. 289-309.

Román, B. (2016). Ética en los servicios sociales. Barcelona: Herder.

Román, B. (2018). "El reconocimiento mutuo: por una ética de los servicios sociales”. En D. García et al. (coords.), Ética y filosofía política: Homenaje a Adela Cortina (pp. 383-394). Madrid: Tecnos.

Salcedo, D. (2010). "Los fundamentos normativos de las profesiones y los deberes de los trabajadores sociales". Trabajo Social Global, 1 (1), pp. 10-38.

Seoane, J. A. (2011). “¿Qué es una persona con discapacidad?”. Ágora, 30(1), pp. 143-161.

Toboso, M. (2018). "Diversidad funcional: hacia un nuevo paradigma en los estudios y en las políticas sobre discapacidad”. Política y Sociedad, 55, 3, pp. 783-804.

Toboso, M. y Guzmán, F. (2010). "Cuerpos, capacidades, exigencias funcionales... y otros lechos de Procusto". Política y Sociedad, 47 (1), pp. 67-83.

Úriz, Ma J. y Salcedo, D. (2017). "Presentación del monográfico: Ética y Trabajo Social”. Cuadernos de Trabajo Social, 30(1), pp. 17-21. 
Úriz, Ma J. (coord.) (2019). La necesaria mirada ética en Trabajo Social. Madrid: Ediciones Paraninfo y Consejo General del Trabajo Social.

Verde-Diego, C. y Cebolla, O. (2017). "Deontología profesional: la ética denostada". Cuadernos de Trabajo Social, 30(1), pp. 77-95.

Winner, L. (2007). "Is there a right to shape technology?". Argumentos de Razón Técnica, 10, pp. 199-213. Recuperado de http://institucional.us.es/revistas/argumentos/10/art_11_rea10.pdf

Young, I. M. (2011). Responsabilidad por la justicia. Madrid: Morata. 